\title{
ANALES DE

Normalización transitoria de CK en un paciente con distrofia de Becker y tumor germinal testicular; ¿un efecto de la quimioterapia?

\section{Sr. Director:}

La distrofia muscular de Becker es una miopatía hereditaria de carácter recesivo ligada al cromosoma $\mathrm{X}$ que guarda semejanzas con la distrofia de Duchenne pero con una evolución más lenta (2). La incidencia de la distrofia de Becker es escasa, uno de cada 18000 personas (1), y son pocos los casos publicados que han desarrollado neoplasias $(3,4)$; en concreto, no hemos encontrado ninguno de tumor germinal en enfermos con distrofia de Becker (Medline 1966-2005). No hay datos tampoco sobre la respuesta de esta enfermedad al empleo de fármacos citostáticos. Presentamos la evolución de un paciente con distrofia de Becker diagnosticado de carcinoma embrionario avanzado en que las cifras de creatín-cinasa (CK) se normalizaron a lo largo del tratamiento con quimioterapia.

Varón, sin alergias ni hábitos tóxicos, diagnosticado de distrofia muscular de Becker a los ocho años; su hermano y un hermano de su madre padecen la misma enfermedad. A la edad de 20 años fue diagnosticado de carcinoma embrionario testicular con afectación ganglionar retroperitoneal. Los marcadores tumorales en el momento de iniciar el tratamiento mostraban elevación de beta-HCG (1489 U/1; normal hasta 1 U/1) y LDH (556 U/1; normal hasta $460 \mathrm{U} / 1)$. El paciente fue tratado de acuerdo con las directrices del Grupo Germinal (5). Recibió tres ciclos de quimioterapia: dos ciclos de BEP seguidos de un ciclo de EP. En este esquema se administra diariamente cisplatino $\left(25 \mathrm{mg} / \mathrm{m}^{2}\right)$ y etopósido $\left(100 \mathrm{mg} / \mathrm{m}^{2}\right)$ a lo largo de cuatro días; esta pauta se repite cada tres semanas por un total de tres ciclos. Y también incluye la infusión de $30 \mathrm{mg}$ diarios de bleomicina los días 1, 8, 15, 22, 29 y 36. Como pauta antiemética se administraron a diario $8 \mathrm{mg}$ de ondansetrón y $8 \mathrm{mg}$ de dexametasona durante los días en que recibía cisplatino y etopósido. Mientras se mantuvo el tratamiento citostático las cifras de CK se mantuvieron dentro de límites normales (Fig. 1). En la determinación practicada tres meses después

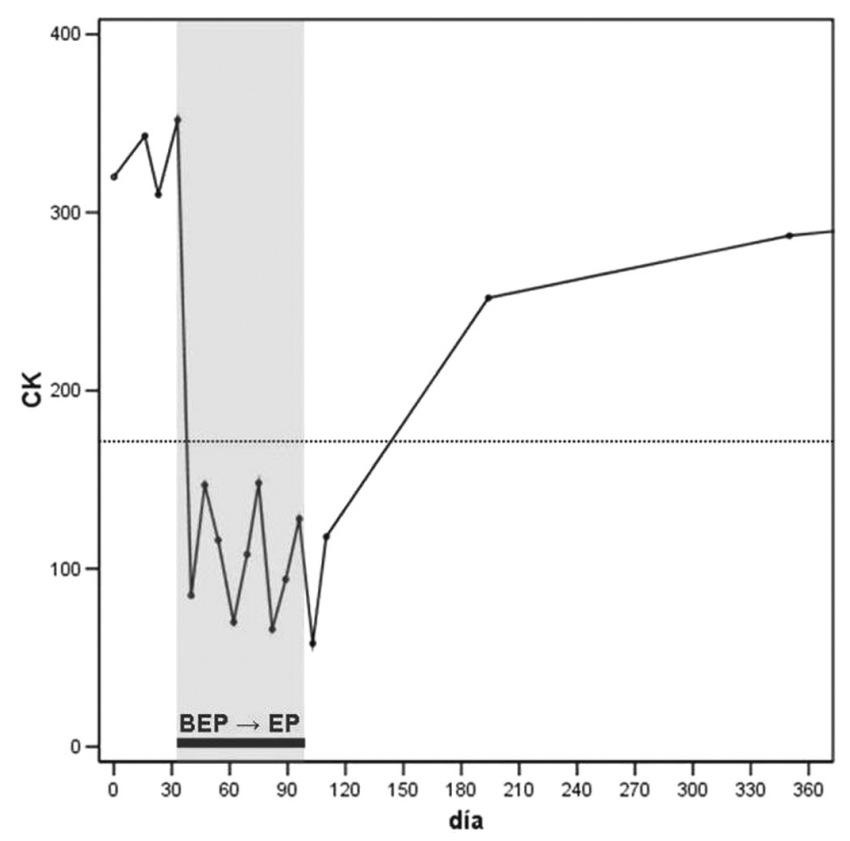

Fig. 1. Evolución de los valores de CK (U/I) en plasma. La franja gris indica los días en que se administró el tratamiento con quimioterapia y la línea discontinua el umbral de las concentraciones normales de CK.

del final de la quimioterapia las cifras de CK se habían elevado de nuevo y estos valores altos han persistido a lo largo de los cinco años de seguimiento. En todo este tiempo el paciente mantiene la respuesta completa que alcanzó con la quimioterapia.

No se ha descrito ningún tratamiento que se pueda considerar estándar en la distrofia muscular de Becker (6). Aunque en este paciente se asocia el empleo de quimioterapia (BEP) con una reducción de los niveles de $\mathrm{CK}$, no hay datos que respalden un posible efecto de la quimioterapia antineoplásica en 
esta enfermedad. De hecho, sólo se han presentado casos puntuales de enfermos con distrofia de Becker que hayan sido tratados con quimioterapia tras desarrollar algún tipo de tumor (3). Y en ellos no se ha descrito ningún beneficio sobre la patología muscular. En la distrofia muscular de Duchenne se ha apreciado que la administración de corticoides suele inducir una reducción de los niveles plasmáticos de CK (7). En la distrofia de Becker, aunque los datos publicados son más escasos, parece que el efecto es similar y que se asocia con una mejoría clínica y analítica (8). Sin embargo, los efectos secundarios a medio y largo plazo de los corticoides desaconsejan su empleo mantenido en este tipo de patología crónica degenerativa. En Oncología, el empleo de regímenes de quimioterapia especialmente emetógenos, como este que incluye cisplatino, suele precisar la administración de un tratamiento de soporte antiemético que incluye, al menos, un antagonista de los receptores 5-HT3 y un corticoide (9). El paciente que presentamos recibió dosis altas de corticoides como profilaxis antiemética: un total de $32 \mathrm{mg}$ de dexametasona a lo largo de cada uno de los tres ciclos del tratamiento (10). Aunque la aparente mejoría de los niveles de $\mathrm{CK}$ ha coincidido con la administración de la quimioterapia, los datos de la literatura apuntan a que lo más probable sea que este efecto se haya debido a la administración de corticoides $(7,8)$. Esta experiencia ayuda a recordar que en pacientes que reciben tratamiento citostático ciertos efectos pueden no deberse tanto a la propia quimioterapia como a los fármacos que se administran como tratamiento de soporte.

\section{A. S. Rubiales, M. L. del Valle, L. A. Flores, S. Hernansanz, C. Gutiérrez}

Servicio de Oncología. Hospital Clínico Universitario. Valladolid

1. Emery AEH. Muscular dystrophies. Lancet 2002; 359: 687-95.

2. Restrepo S. New treatment alternatives for Duchenne and Becker muscular dystrophy. Neurology 2004; 62: E10.

3. Uotani H, Hirokawa S, Saito F, Tauchi K, Shimoda M, Ishizawa S, et al. Non-Hodgkin's lymphoma of the ascending colon in a patient with Becker muscular dystrophy: report of a case. Surg Today 2001; 31 : 1016-9.

4. Cereda S, Cefalo G, Terenziani M, Catania S, Fossati-Bellani F. Becker muscular dystrophy in a patient with Hodgkin's disease. J Pediatr Hematol Oncol 2004; 26: 72-3.

5. Germà-Lluch JR, García del Muro X, Maroto P, Paz-Ares L, Arranz $\mathrm{JA}$, Gumà $\mathrm{J}$, et al. Clinical pattern and therapeutic results achieved in 1490 patients with germ-cell tumours of the testis: the experience of the Spanish Germ-Cell Cancer Group (GG). Eur Urol 2002; 42: $553-63$.

6. Voisin V, de la Porte S. Pharmacological treatments for Duchenne and Becker dystrophies. J Soc Biol 2005; 199: 17-28.

7. Backman E, Henriksson KG. Low-dose prednisolone treatment in Duchenne and Becker muscular dystrophy. Neuromuscul Disord 1995; 5: 233-41.

8. Johnsen SD. Prednisone therapy in Becker's muscular dystrophy. J Child Neurol 2001; 16: 870-1.

9. Schmoll HJ, Souchon R, Krege S, Albers P, Beyer J, Kollmannsberger $\mathrm{C}$, et al. European consensus on diagnosis and treatment of germ cell cancer: a report of the European Germ Cell Cancer Consensus Group (EGCCCG). Ann Oncol 2004; 15: 1377-99.

10. The Antiemetic Subcommittee of the Multinational Association of Supportive Care in Cancer (MASCC). Prevention of chemotherapyand radiotherapy-induced emesis: results of the 2004 Perugia International Antiemetic Consensus Conference. Ann Oncol 2006; 17: $20-8$.

\section{Insuficiencia respiratoria aguda como manifestación inicial de esclerosis lateral amiotrófica}

\section{Sr. Director:}

La esclerosis lateral amiotrófica (ELA) es una enfermedad degenerativa caracterizada por la afectación de la motoneurona espinal que ocasiona atrofia muscular progresiva. Su incidencia se estima en 1-3 casos/100.000 habitantes/año, siendo más frecuente en varones.

La insuficiencia respiratoria secundaria a enfermedad de motoneurona suele desarrollarse una vez diagnosticada la enfermedad como consecuencia de la progresión natural de la misma por debilidad de los músculos respiratorios o de forma aguda desencadenada por una infección respiratoria, siendo excepcional su presentación como primer síntoma de la enfermedad (1). Describimos el caso de un paciente que ingresó por fallo respiratorio agudo secundario a parálisis diafragmática bilateral como primera manifestación de ELA.

Presentamos el caso de un paciente de 71 años que ingresa cianótico y con bajo nivel de conciencia. En sus antecedentes personales destacaba el diagnóstico de hipertensión arterial, hipercolesterolemia y cardiopatía isquémica asintomática desde hacía dos años. El paciente refería desde hacia unos seis meses disnea en decúbito con episodios de disnea paroxística nocturna, que había aumentado de forma progresiva en los últimos dos meses, sin otra sintomatología acompañante. La mañana del ingreso lo encuentra su mujer en la cama con bajo nivel de conciencia, cianótico y no responde a órdenes. En la exploración física estaba afebril, normotenso, cianótico y con bajo nivel de conciencia, no presentaba otros datos de afectación neurológica y el resto de la exploración era normal. La gasometría realizada mostraba una hipoxemia severa (PO2 45) e hipercapnia (PCO2 91) con acidosis respiratoria por lo que fue necesaria la intubación y ventilación mecánica. La analítica realizada con hemograma, bioquímica con creatinin fosfoquinasa, aldolasa, magnesio, hormonas tiroideas, ANAs, factor reumatoide, proteina $\mathrm{C}$ reactiva, inmunoglobulinas, complementos $\mathrm{C} 3$ y $\mathrm{C} 4$ fueron normales, además se descartó intoxicación por fármacos depresores del sistema nervioso central, metales pesados y tóxicos. La radiografía de tórax mostraba elevación de ambos diafragmas. El paciente es desintubado a los pocos días y el estudio respiratorio realizado mostraba un patrón restrictivo con afectación diafragmática bilateral. Las pruebas de función respiratoria acostado mostraban una disminución de FVC $(719,19 \%)$ y FEV1 (520, 18\%) con IND del $91 \%$, estos valores mejoraban sentado y tras ventilación a presión positiva intermitente, los valores de presión espiratoria muscular (PEM) eran de 19 (16\%) y la presión inspiratoria muscular (PIM) de 10 (14\%). La afectación diafragmática fue demostrada por fluoroscopia. El paciente fue tratado con ventilación a presión positiva intermitente por vía nasal con buena respuesta clínica. El estudio neurofisiológico de conducción de nervios frénicos fue normal. Tras presentar una mejoría clínica significativa es dado de alta para continuar estudio ambulatorio y dirigido a la consulta de neurología. A los 4 meses es visto en la consulta de neurología donde refiere debilidad en mano derecha. En interrogatorio dirigido el paciente relata cuadro de varios meses de evolución de debilidad en manos. En exploración presentaba debilidad en ambas manos con leve dificultad en aprensión de objetos, ligera atrofia de músculos interóseos, reflejos osteotendinosos vivos y fasciculaciones en extremidades inferiores sin otros datos. Se solicita estudio neurofisiológico que detecta la presencia de signos de denervación con fasciculaciones y fibrilaciones en varios músculos de las extremidades compatible con afectación de motoneurona inferior, las velocidades de conducción eran 